\title{
Characterization of bacterial epibionts on the cyanobacterium Trichodesmium
}

\author{
L. R. Hmelo ${ }^{1,2}$, B. A. S. Van Mooy ${ }^{1}$, T. J. Mincer ${ }^{1, *}$ \\ ${ }^{1}$ Department of Marine Chemistry and Geochemistry, Woods Hole Oceanographic Institution, Woods Hole, \\ Massachusetts 02543, USA \\ ${ }^{2}$ Present address: Department of Microbiology, School of Medicine, University of Washington, Seattle, \\ Washington 98195, USA
}

\begin{abstract}
Interest in Trichodesmium, a nitrogen-fixing genus of Cyanobacteria, has been fueled by its prominent role in the marine nitrogen cycle. However, it is often overlooked that Trichodesmium occur in the ocean as colonies and are only one member of a complex microbial consortium. In the present study, we used 16S rRNA gene sequences to phylogenetically classify the communities associated with 2 morphological types of Trichodesmium colonies, tufts and puffs, which were collected at the Bermuda Atlantic Time Series (BATS) site in the Sargasso Sea. Both Trichodesmium morphotypes were most closely related to $T$. thiebautii at $\geq 99 \%$ identity. Noncyanobacterial sequences from both types of colonies were dominated by Flavobacteria, Sphingobacteria, and Alphaproteobacteria. However, the epibiotic communities possessed significantly lower diversity than bacterioplankton; major seawater planktonic taxa, such as the SAR11 clade and Archaea, were conspicuously absent. Moreover, several epibiotic taxa appeared to be novel. Among the tuft or puff 16S rRNA clone libraries constructed in the present study, epibionts sharing common operational taxonomic units at the 97 percent sequence identity (PSI) threshold or higher were not observed, presenting the possibility that these 2 morphologies could select for different epibiotic communities. While our data are representative of a single sample point in time and space, these data suggest that Trichodesmium possess an epibiotic microbial community of relatively low diversity, distinct from that observed in bacterial picoplankton.
\end{abstract}

KEY WORDS: Trichodesmium - Epibiont $\cdot$ Cyanobacteria $\cdot$ Cultivation-independent $\cdot$ Pelagic microbial community

Resale or republication not permitted without written consent of the publisher

\section{INTRODUCTION}

Scientific interest in the cyanobacterial genus Trichodesmium has largely been driven by the significant role of these microbes as $\mathrm{N}_{2}$ fixers (Capone et al. 1997, Karl et al. 1997). They are capable of fixing at least $80 \mathrm{Gt} \mathrm{N} \mathrm{yr}^{-1}$ in extremely low-nutrient, oligotrophic marine environments; as such, they are a major source of fixed carbon and reduced nitrogen to these environments and possibly fuel intense microbial activity in surface waters (Letelier \& Karl 1996, Capone et al. 1997, Carpenter et al. 1997, Sohm et al. 2011).
Without exception, heterotrophic bacteria, and frequently filamentous Cyanobacteria, are observed attached to the surface of Trichodesmium spp. (Herbst \& Overbeck 1978, Paerl et al. 1989, Siddiqui et al. 1992). Cell densities of bacterial epibionts of Trichodesmium are reported to range from $8.2 \times 10^{8}$ cells $\mathrm{ml}^{-1}$ (Sheridan et al. 2002) to $2.6 \times 10^{11} \mathrm{cells} \mathrm{ml}^{-1}$ (Paerl 1982 ), which is $\sim 3$ to 5 orders of magnitude more concentrated than typical counts of planktonic bacteria in the euphotic zone of the open ocean. It is extraordinarily difficult to isolate Trichodesmium spp. in axenic culture, suggesting that they have evolved an essential relationship with their epibionts (Waterbury 
1991). Heterotrophic bacteria are known to colonize the surface of marine eukaryotic algae (Fisher et al. 1998, Sapp et al. 2007) and Cyanobacteria (Herbst \& Overbeck 1978, Paerl 1982, Siddiqui et al. 1992, Nausch 1996, Sheridan et al. 2002, Stevenson \& Waterbury 2006, Simmons et al. 2008) with some associations being quite specific (Paerl \& Gallucci 1985, Fisher et al. 1998, Stevenson \& Waterbury 2006, Tuomainen et al. 2006). For example, the cyanobacterium Anabaena sp. strain SSM-00 transfers fixed nitrogen to its epibiont Rhizobium sp. strain WH2K (Behrens et al. 2008). In many cases, associations between heterotrophic bacteria and phytoplankton are quite specific (Fisher et al. 1998, Paerl \& Gallucci 1985, Stevenson \& Waterbury 2006, Tuomainen et al. 2006). In the case of Anabaena sp. strain SSM-00 and Rhizobium sp. strain WH2K, transfer of fixed nitrogen from host to epibiont has been shown (Behrens et al. 2008).

The production of organic matter by phytoplankton and the concomitant release of fixed carbon and nitrogen into the upper ocean is a major geochemical process in the ocean. Viral lysis and programmed cell death are 2 mechanisms that are known to mediate the termination of Trichodesmium blooms and subsequent release of fixed nutrients into the environment (Hewson et al. 2004, Berman-Frank et al. 2007). Attached bacteria contribute to the transfer of fixed nutrients from Trichodesmium to the upper ocean by consuming Trichodesmium-produced organic exudates (Herbst \& Overbeck 1978) and funneling this material into the microbial loop; bacteria thereby retain nitrogen fixed by Trichodesmium in the euphotic layer of the ocean (Nausch 1996).

Nitrogen fixed by Trichodesmium fuels new production, which is potentially a major driver for carbon export into the deep ocean. If degradation of these colonies is partially mediated by attached bacteria, these organisms could influence the residence time of fixed nitrogen and carbon in the upper ocean as well as the composition of the material exported into the deep ocean. The heterotrophic epibionts attached to nitrogen-fixing Cyanobacteria may also achieve broad ecological impacts by influencing the longevity of blooms by recycling organic matter and nutrients (Tuomainen et al. 2006). These epibionts are also suspected to aid the efficiency of Trichodesmium iron solubilization and uptake by contributing to the formation of anoxic microzones within Trichodesmium colonies (Roe et al. 2012).

Individual Trichodesmium cells typically form multi-cell trichomes, which can bundle together in multi-trichome colonies (Carpenter et al. 2004). These colonies tend to be dominated by 2 morpho- logic types, a spherical 'puff' type and a fusiform 'tuft' type. Bacteria on tuft-type colonies have been observed to occur in higher densities (Sheridan et al. 2002) and exhibit higher hydrolytic enzyme activity (Nausch 1996) relative to those on puff-type colonies, although the diversity of metazoa and microzooplankton associated with puff-type colonies appears to be greater than that associated with tufts (Sheridan et al. 2002). Considering the global environmental significance of this specific algal-bacterial association, the identity of ubiquitous heterotrophic epibionts associated with Trichodesmium spp. has been relatively understudied. Here, we report results of a culture-independent 16S rRNA gene sequencebased clone library survey of the microbial epibiont community associated with Trichodesmium colonies collected in the Sargasso Sea.

\section{MATERIALS AND METHODS}

\section{Sample collection}

Trichodesmium spp. colonies were collected under non-bloom conditions (i.e. no obvious bloom was observed during any time of collection) in September 2008 on the RV 'Atlantic Explorer' at the Bermuda Atlantic Time Series (BATS) station. Aggregates were collected from the near surface (the upper $\sim 20 \mathrm{~m}$ ) by a hand-held $130 \mu \mathrm{m}$ plankton net, and individual colonies were gently picked using an inoculating loop. Colonies were sequentially washed 3 times with $0.2 \mu \mathrm{m}$ filtered seawater. Individual colonies were preserved for DNA extraction. Colonies were preserved in SET buffer $(0.75 \mathrm{M}$ sucrose, $50 \mathrm{mM}$ Tris pH 8, 40 mM EDTA pH 8) and frozen in liquid $\mathrm{N}_{2}$ at sea and then transferred to a $-80^{\circ} \mathrm{C}$ freezer in Woods Hole.

\section{DNA extraction and clone library construction}

Clone libraries of bacterial $16 \mathrm{~S}$ rRNA gene sequences were constructed from 2 samples. One sample consisted of 10 puff-type colonies, and the other sample consisted of 10 tuft-type colonies. DNA was obtained according to a protocol adapted from DeLong et al. (2006). Aliquots of community Trichodesmium spp. DNA (25 to $100 \mathrm{ng}$ ) were added as template to polymerase chain reactions (PCR) for amplification of the SSU rRNA gene sequence. Each PCR consisted of the following (all amounts are final concentrations): $0.2 \mathrm{mM}$ each dNTPs, $0.5 \mu \mathrm{M}$ each 
forward primer 27F (5'-AGA GTT TGA TCM TGG CTC AG-3') and reverse primer 1492R (5'-TAC GGY TAC CTT GTT ACG ACT T-3') (primers were custom synthesized by Invitrogen), 2 units 'Easy A' thermostable proofreading polymerase (Stratagene), and $1 \times$ 'Easy A' reaction buffer containing $2 \mathrm{mM} \mathrm{MgCl} \mathrm{M}_{2}$ for a $20 \mu \mathrm{l}$ final reaction volume. PCR amplification conditions were as follows: an initial denaturation step of 2 min at $94^{\circ} \mathrm{C}, 30 \mathrm{~s}$ at $94^{\circ} \mathrm{C}, 30 \mathrm{~s}$ at $55^{\circ} \mathrm{C}$, and $90 \mathrm{~s}$ at $72^{\circ} \mathrm{C}$. The final 3 steps were repeated for a total of 30 cycles. To avoid bias, the amplification products were monitored, and we determined that these conditions represented the minimum number of cycles needed to obtain sufficient product for cloning while avoiding saturation of the reaction (Suzuki \& Giovannoni 1996). Reconditioning PCR was carried out to reduce heteroduplex formation (Thompson et al. 2002) as follows: initial reaction products were diluted 10 -fold and re-amplified using parameters identical to above, except that only 3 thermal cycles were performed. Triplicate PCR amplifications were pooled and cloned into PCR 4TOPO plasmid vectors using a TOPO TA cloning kit (Invitrogen). From each library, 384 clones were picked, and the clone insert DNA was amplified using PCR consisting of the following (all reagents reported at final concentrations): $0.2 \mathrm{mM}$ each dNTPs, $0.5 \mu \mathrm{M}$ each forward primer M13F (5'-GTA AAA CGA CGG CCA G-3') and reverse primer M13R (5'-CAG GAA ACA GCT ATG AC-3') (Invitrogen), and 1 U Paq5000 DNA polymerase (Stratagene) in $1 \times$ Paq5000 reaction buffer containing $2.25 \mathrm{mM}$ $\mathrm{MgCl}_{2}$ for a $20 \mu \mathrm{l}$ final reaction volume. A total of 35 reaction cycles were completed using the same parameters as above. In total, 384 bacterial SSU rRNA clones were prepared for sequencing from each library.

\section{Sequencing}

Clone inserts were sequenced in the forward direction using the primer 27F. End-sequencing was performed offsite either by MWG-Operon or Agencourt Biosciences. A total of 339 raw sequences were generated from the tuft-colony library, and 331 raw sequences were generated from the puff-colony library. Sequences were typically between 700 and 750 base pairs in length.

Raw sequences were aligned via the web-based SINA aligner (www.arb-silva.de/aligner/). Aligned sequences were imported into ARB (Ludwig et al. 2004) (version 07.12.07). The sequences were de- replicated at 97,99 , and $100 \%$ identity thresholds using FastGroup II (Yu et al. 2006) (http://biome.sdsu. edu/fastgroup). Unique sequences were submitted to the Bellerophon server (Huber et al. 2004) (http:// greengenes.lbl.gov/cgi-bin/nph-bel3_interface.cgi) to identify putative chimeras. Sequences submitted to Bellerophon were internally aligned using ClustalW and evaluated with a Huber-Hugenholtz correction and a window size of 200. Sequences identified as chimeric by Bellerophon were confirmed or disregarded with information from the Ribosomal Database Project (RDP II) chimera detection software (Cole et al. 2003) (http://rdp.cme.msu.edu/). Chimeric sequences were excluded from further analyses (5 sequences were removed from the tuft-colony library, and 6 sequences were removed from the puff-colony library). An additional 22 sequences were excluded from the tuft-library and 20 additional sequences were excluded from the puff-library because the sequences were very short $(<430 \mathrm{bp})$.

\section{PCR with archaeal and eukaryotic primers}

Trichodesmium total community DNA extracts were screened for the presence of archaeal 16S rRNA genes and eukaryotic 18S rRNA genes. The PCR was performed as described above, using Paq5000 DNA polymerase, with the following modifications: archaeal primers Ar20F (5'-TTC CGG TTG ATC CYG CCR G-3') and Ar958R (5'-YCC GGC GTT GAM TCC AAT T-3') were added to a final concentration of $0.5 \mu \mathrm{M}$ with an annealing temperature of $60^{\circ} \mathrm{C}$. The parameters for eukaryotic $18 \mathrm{~S}$ rRNA gene amplification were as follows: primers EukF (Escherichia coli forward position 7, 5'-AAC CTG GTT GAT CCT GCC AGT-3') and EukR (E. coli reverse position 1534, 5'-TGA TCC TTC TGC AGG TTC ACC TAC-3') were added at a final concentration of $0.5 \mu \mathrm{M}$ with an annealing temperature of $65^{\circ} \mathrm{C}$. DNA from a fosmid template clone 4B7 (a member of the Group I Crenarchaea) (Stein et al. 1996) and a eukaryotic enrichment produced from seawater collected during HOTS cruise 179 (http://hahana.soest. hawaii.edu/hot/hot_jgofs.html) at Station ALOHA at $25 \mathrm{~m}$ were used as positive amplification controls for archaeal and eukaryote screening, respectively.

\section{Taxonomic assignments and phylogenetic analyses}

The Ribosomal Database Project II Classifier (Cole et al. 2003) was used to assign provisional taxonomic 
affiliations to $97 \%$ similar operational taxonomic units (OTUs). BLASTn searches (Altschul et al. 1997) of the National Center for Biotechnology Information 16S rRNA gene sequence database were performed and showed taxonomic placements of many of our clones to be novel at or above the genus level, explaining their low bootstrap values in the automatic classifier. The proportions of major taxonomic groups were calculated, and the BLASTn results are available in Tables S1 \& S2 in the supplement at www.int-res.com/articles/suppl/a067p001_supp.pdf. All BLASTn searches were performed with the GenBank database updated on 1 January 2010.

Rarefaction, coverage, and richness were all calculated at a 97 percent identity threshold (PSI) using the software resource Fast Group II (Yu et al. 2006). Confidence intervals of 95 and $98 \%$ were calculated for rarefaction results using variance data provided in the Fast Group II calculations. The coverage of our clone libraries (percentage of actual species richness detected) was calculated according to Good (1953) and Chao \& Yang (1993). The former algorithm estimates coverage related to relatively rare OTUs, while the latter estimates coverage based on the abundance of dominant OTUs, providing a lower and upper bound on coverage, respectively. Species rich- ness was estimated using the Chao1 nonparametric richness estimator (Chao 1987) (Table 1), yielding the probable number of OTUs in the sample on the basis of singletons and doubletons detected in the clone library (Chao 1987). The Shannon diversity index, which takes into account species richness and evenness of species distribution, was calculated according to the equations provided by Pielou (1966), as were approximations of the variance of resultant confidence intervals. All sequences were deposited in GenBank under accession nos. GU725472 to GU726134.

\section{RESULTS}

\section{Cyanobacteria}

Although this study was focused on the epibiont communities associated with Trichodesmium spp., we chose a DNA extraction method that has been shown to lyse a wide range of cells (DeLong et al. 2006). As a result, high numbers of cyanobacterial 16S rRNA gene sequences were recovered (the puff library yielded 143 cyanobacterial clones from a total of 305 community clones, and 213 cyanobacterial clones were obtained from 312 total tuft library community clones). These data provided a valuable insight into the cyanobacterial 'base' of the colonies (Fig. 1).

In total, $100 \%$ of the cyanobacterial clones (143 total) in the puffcolony library were related to Trichodesmium thiebautii (Genbank accession no. AF013027) at the 99 PSI threshold. The tuft colonies contained a more diverse cyanobacterial community, although all of the tuft-colony derived cyanobacterial clones were determined to be members of the Order Oscillatoriales that includes the genus Trichodesmium. In total, $69 \%$ of clones $(\mathrm{n}=148)$ were related to $T$. thiebautii at 99 PSI. However, $31 \%$ of the clones $(\mathrm{n}=65)$ were most closely related (93 to 96 PSI) to an uncultured bacterium (EF630220) that shared 92 PSI with a cultured Limnothrixlike species (GenBank accession no. EF088338). The Limnothrix-like phylotypes were included in the cal- 


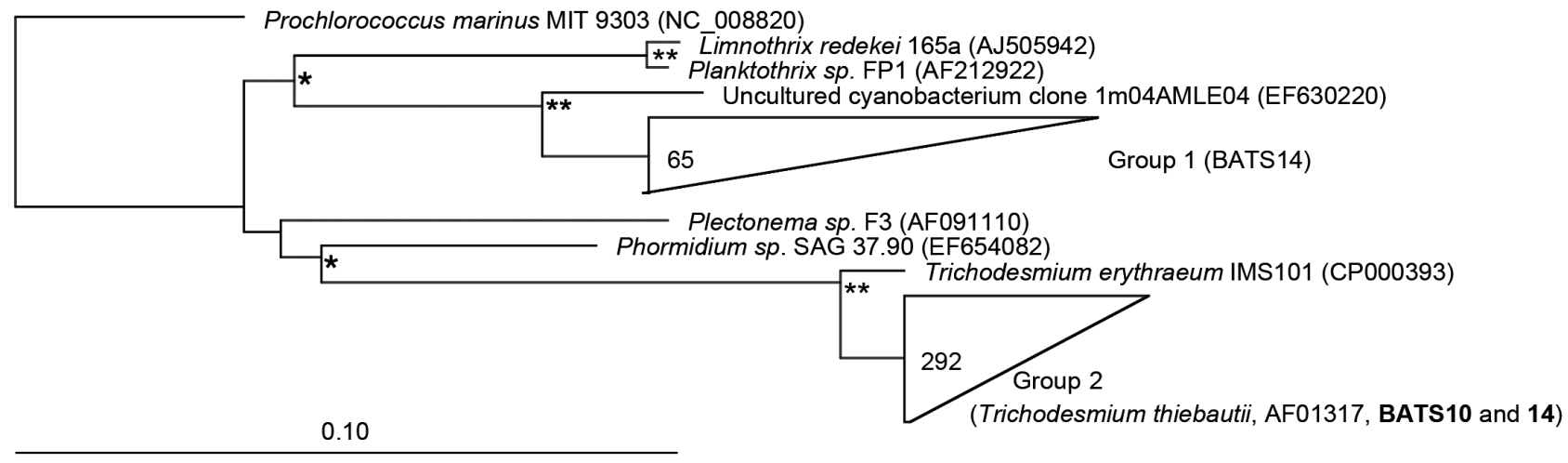

Fig. 1. Phylogenetic tree containing cyanobacterial 16S rRNA gene sequences recovered from Trichodesmium colonies in the present study. This tree was created using the neighbor-joining algorithm in ARB and bootstrapped 1000 times using Phylip (version 3.68). ${ }^{*}$ bootstrap values of $\geq 60 \% ;{ }^{* *}$ bootstrap values of $\geq 90 \%$. Sequences generated in the present study in bold. Accession numbers are in parentheses following all sequences. Sequences within Group 1 are at least $97 \%$ identical to the sequence BATS14_298, accession no. GU725542. Sequences within Group 2 are at least $97 \%$ identical to the sequence BATS14_001, accession no. GU725789. BATS10 identifies puff-colony library sequences, and BATS14 identifies tuft-colony sequences. The scale bar corresponds to 10 base substitutions per 100 nucleotide positions

culations of epibiotic bacterial richness, evenness, and rarefaction estimations of diversity.

\section{Overview of epibiotic bacteria}

The puff-colony and tuft-colony libraries displayed some similarities at the class level (Fig. 2a), although there was significant heterogeneity at more specific ranks. As is evident in Figs. 3 \& 4, epibiotic OTUs recovered from the puff colony and the tuft colony are mutually exclusive. The

Fig. 2. Class-level 16S rRNA gene sequence-based phylogenetic composition of (a) puff-colony and tuft-colony epibiont communities and (b) Sargasso Sea bacterioplankton (for comparison, data from Carlson et al. 2009). Values listed adjacent to each 'wedge' of the pie chart provide the number of clones in that category followed by the percentage (in parentheses) of the total clones recovered (excluding clones related to Trichodesmium). The total number of clones recovered is listed underneath each chart. Classifications were made using the Ribosomal Database Project II automatic classifier. Sequences were assigned to the most specific taxonomic category that could be assigned with $80 \%$ bootstrap confidence. For more detailed phylogenetic analysis of 'unclassified' sequences, see Figs. $3 \& 4$
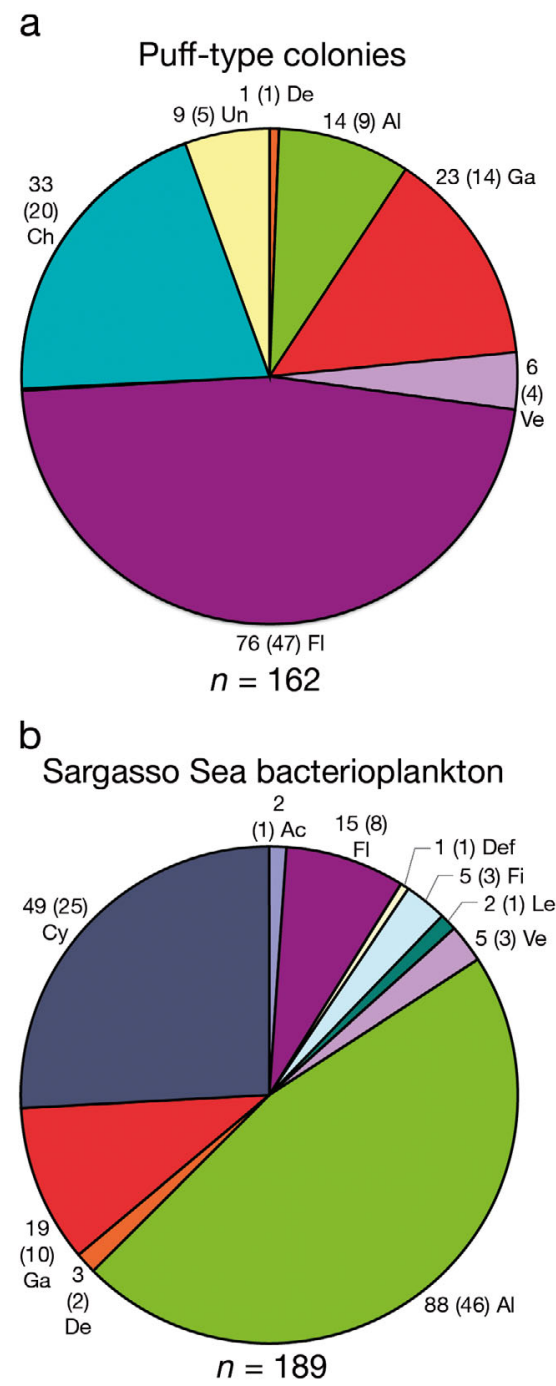

Tuft-type colonies

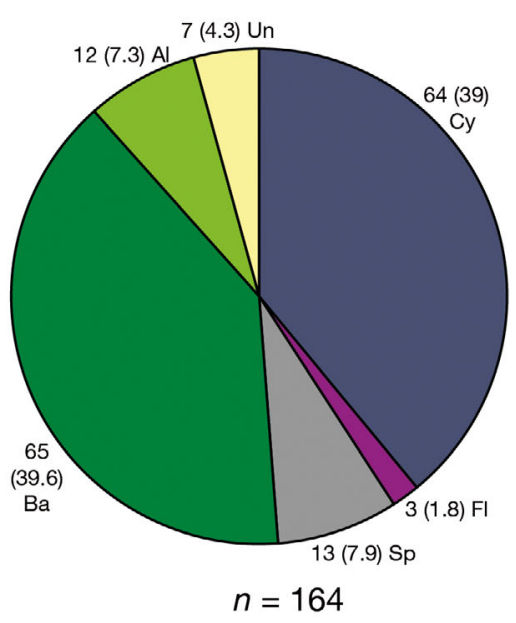

Gammaproteobacteria (Ga)

$\square$ Alphaproteobacteria (Al)

口 Flavobacteria (FI)

$\square$ Sphingobacteria (Sp)

$\square$ Deltaproteobacteria (De)

$\square$ Bacteroidetes, unclassified (Ba)

口 Verucomicrobia (Ve)

$\square$ Unclassified bacteria (Un)

$\square$ Chloroflexi (Ch)

Cyanobacteria (Cy)

$\square$ Deferribacteres (Def)

$\square$ Firmicutes (Fi)

$\square$ Lentispaerae (Le)

$\square$ Actinobacteria (Ac) 


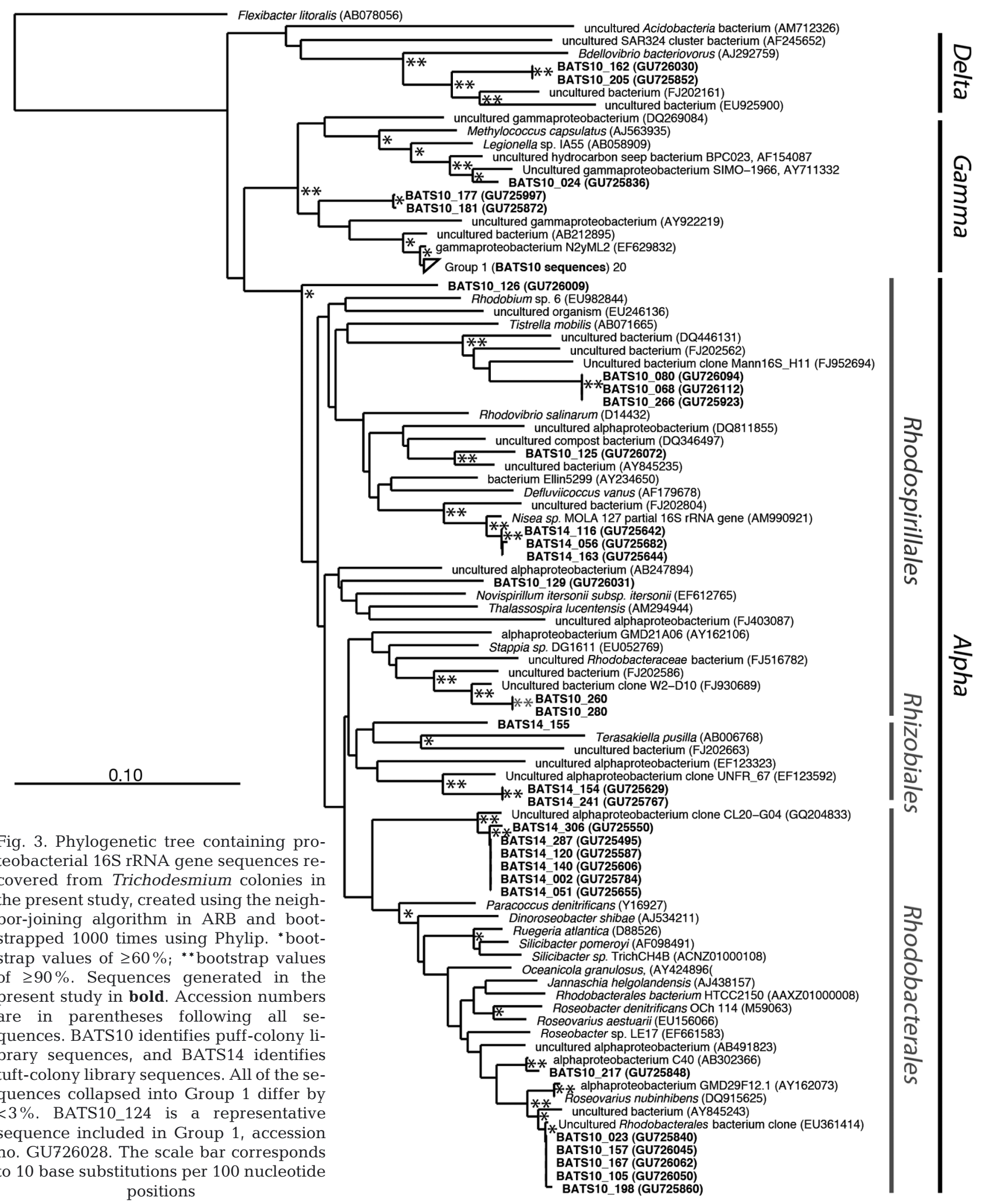

Ribosomal Database Project II Classifier (Cole et al. 2003) was used to assign provisional taxonomic assignments, which were refined using ARB. Using an $80 \%$ bootstrap confidence threshold within the RDP II classifier, we determined that Flavobacteria composed the greatest percentage $(47 \%)$ of non- 


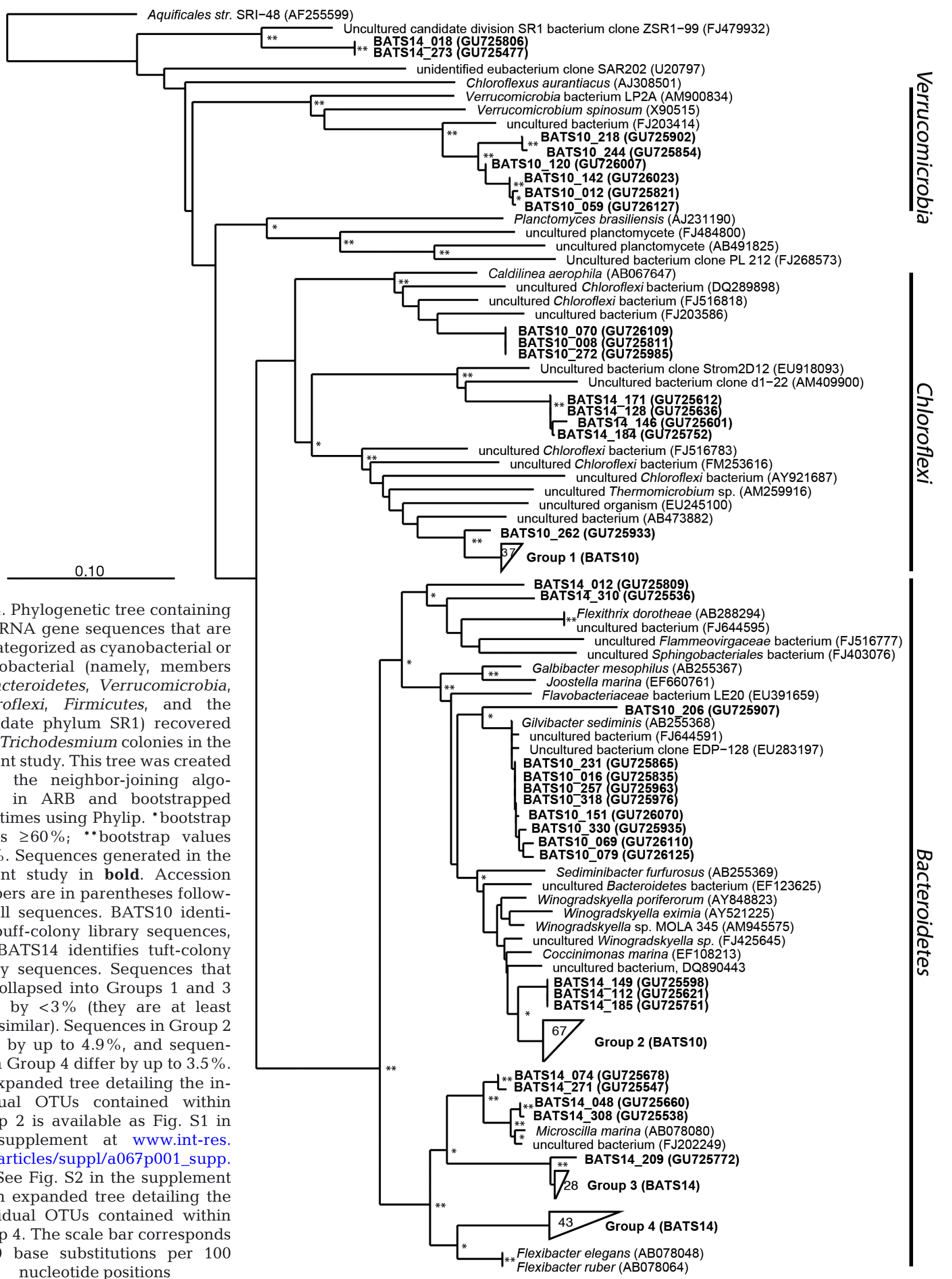


cyanobacterial clones from the puff-colony library, with Chloroflexi (20\%) second most abundant (Fig. 2). Flavobacteria were represented in the tuftcolony library $(2 \%)$, while Sphingobacteria, which were entirely absent from the puff-colony library, were represented by $8 \%$ of the clone sequences. 'Unclassified' Bacteroidetes (unclassifiable at an $80 \%$ bootstrap threshold) composed a large percentage $(40 \%)$ of the total tuft-colony epibiotic community and were most closely related to the class Sphingobacteria (see Fig. 4, Groups 3 and 4). Alphaproteobacteria composed $7 \%$ of tuft-colony clones, while $4 \%$ remained unclassified.

\section{Epibiotic Alphaproteobacteria}

Alphaproteobacteria are represented in both the puff-colony and tuft-colony clone libraries (Fig. 2). The alphaproteobacterial sequences observed in the puff-colony library were dominated by members of the order Rhodobacterales (79\% of puff-colony associated alphaproteobacterial clones, $50 \%$ bootstrap threshold). The remainder of the puff-colony Alphaproteobacteria clones were determined to be members of the order Rhodospirillales $(7 \%$ ) or were unclassifiable within the Alphaproteobacteria with $>50 \%$ bootstrap confidence $(14 \%$ of puff-colony alphaproteobacterial clones could not be further classified). Alphaproteobacterial sequences associated with the tuft colonies examined in the present study were also associated with Rhodobacterales $(50 \%$ of total tuft-colony alphaproteobacterial clones) and Rhizobiales (8\%). In total, $42 \%$ of tuft-colony alphaproteobacterial clones were classified as Rhodospiralles. Finer scale placement of the Alphaproteobacteria clones is shown in Fig. 3.

\section{Eukaryotes and Archaea}

No gene sequences of archaeal 16S rRNA or eukaryotic 18S rRNA were amplified from the Trichodesmium puff-colony or tuft-colony total community DNA extracts, even though amplification of our positive controls was successful.

\section{Clone library coverage, richness, and diversity}

Clone libraries from aggregate samples of pufftype and tuft-type Trichodesmium colonies were statistically assessed for coverage, richness, and diversity. For comprehensive coverage and richness calculations, we binned sequences by PSI threshold. Richness and diversity data are provided for OTUs at 97, 99, and 100 PSI (Table 1). All sequences related to $T$. thiebautii at the 95 PSI level and higher were subtracted from analyses such that the richness, evenness, and rarefaction estimations of diversity we present pertain only to the epibiotic community.

The coverage of each library was estimated using 2 independent measures that rely on the occurrence of either rare (Good's coverage index) (Good 1953) or abundant (Chao's coverage index) (Chao 1987) OTUs. These estimates indicate that at 97 PSI, the puff-colony library captured 75 to $95 \%$ of actual species richness and the tuft-colony library captured a similar range of 68 to $94 \%$ of actual richness. These percentages of coverage decrease if calculations are considered at 99 or 100 PSI OTUs (data not shown). A complementary indicator of probable species richness (Chao1) (Chao \& Yang 1993) was calculated, and at 97 PSI, the puff-colony library yielded a probable 23 OTUs and the tuftcolony library yielded 21. Due to our library coverage being $<100 \%$, the actual measured richness was lower: 18 OTUs were detected in the puffcolony library, and 15 OTUs were detected in the tuft-colony library. These richness values are likely to be low estimates because we chose to analyze our samples as 97 PSI OTUs, and species richness estimates increase if calculations are considered at 99 or 100 PSI OTUs (see Table 1).

Rarefaction curves were calculated for each Trichodesmium epibiont library to determine the likelihood that our sampling effort was sufficient to produce an unbiased estimate of species richness and diversity in the samples (Fig. 5). In the case of both libraries, the curves approach an asymptote, which indicates that our sampling effort was sufficient to yield reliable richness predictions. The termini of the rarefaction curves of the tuft-library and puff-library do not overlap (Fig. 5), indicating that the difference in richness between the 2 libraries is significant at the $95 \%$ confidence interval. This difference was found not to be significant at the $98 \%$ confidence interval (data not shown). The value of the Shannon index, which considers the evenness of OTU distribution in addition to the OTU richness, is slightly higher in the puff-colony library (1.8) compared to the tuft-colony library $(1.7)$; the $95 \%$ confidence intervals for these richness estimates overlap, indicating that the difference is not significant. 


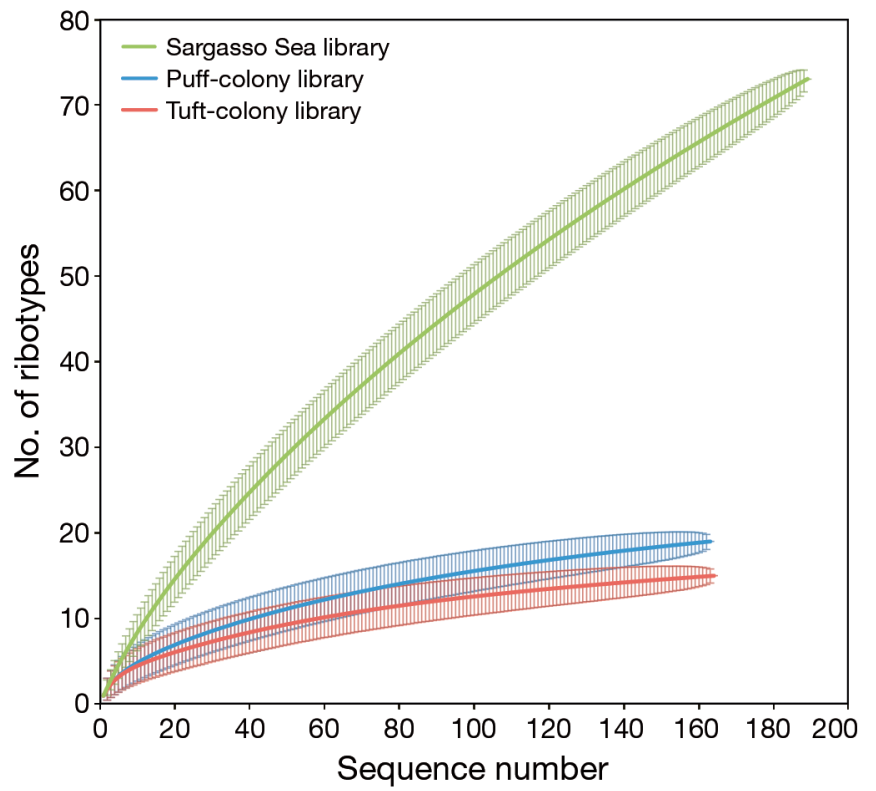

Fig. 5. Rarefaction curve of puff-colony and tuft-colony $16 \mathrm{~S}$ rRNA gene sequence clone libraries generated in the present study as well as a Sargasso Sea clone library (BATS site, $40 \mathrm{~m}$ depth, Carlson et al. 2009). Error bars represent $95 \%$ confidence intervals. All Trichodesmium phylotypes of $\geq 95$ percent sequence identity present in puff-colony and tuft-colony libraries were excluded from the rarefaction calculation

\section{DISCUSSION}

Trichodesmium spp. frequently exist not as individual trichomes but in colonies of trichomes that can occur in distinct morphological varieties and in close association with numerous types of other microbes (Sheridan et al. 2002, Carpenter et al. 2004). It is our observation as well as others (J. Waterbury pers. comm., E. Webb pers. comm.) that Trichodesmium spp. are difficult to obtain and maintain in axenic culture, which could imply an essential dependence of Trichodesmium spp. on its epibiotic bacteria. Relatively little work has been devoted to the Trichodesmium colony as a consortial community. In the present study, we set out to investigate the identity of the bacteria associated with puff-type or tuft-type colonies of wild Trichodesmium spp. and how these bacterial communities compared with that of ambient seawater.

It is well known that the Sargasso Sea and other oligotrophic marine biomes can harbor a high diversity of bacterioplankton. Since the foundational work at BATS by Giovannoni et al. (1990) and Chisholm et al. (1988), it has been recognized that the Sargasso Sea is consistently dominated by major lineages of bacteria such as SAR11, Prochlorococcus, and Syne- chococcus (Morris et al. 2005, Carlson et al. 2009). Using a dataset published by Carlson et al. (2009), we calculated the estimated richness of Sargasso seawater collected at the BATS site from $40 \mathrm{~m}$ and determined a richness estimate of 141 at the 97 PSI threshold (189 clones; Table 1). Similarly, Pommier et al. (2007) found that Sargasso seawater collected at $5 \mathrm{~m}$ had an estimated richness (Chao1) of 150 at the 97 PSI threshold (571 clones). Although values from both the Carlson et al. (2009) dataset and Pommier et al. (2007) were based on samples collected on different cruises than our samples of Trichodesmium colonies, these estimates of the number of OTUs in seawater exceed our estimates for the puff colonies or tuft colonies (23 and 21 OTUs, respectively) by several fold. Thus, we posit that the number of species (i.e. OTUs at 97 PSI) associated with Trichodesmium colonies is likely to be substantially lower than in the surrounding seawater. This suggests that compared to seawater, the phycosphere of Trichodesmium selects for a specific subgroup of organisms. We observed a slightly greater species richness in the puff-colony library (18 OTUs were observed at $97 \mathrm{PSI}$ ) relative to the tuft-colony library (15 OTUs were observed at 97 PSI), an observation which mirrors the richer community of microzooplankton and metazoa previously documented in puff-type colonies (Sheridan et al. 2002). Comparison of $95 \%$ confidence intervals of rarefaction calculations suggests that the observed difference in richness between the 2 libraries is significant (see 'Results' and Fig. 5). Although the observed difference is significant, these data are only representative of colonies sampled on one date at one location. More sampling will be necessary to determine whether higher bacterial community richness on puff colonies relative to tuft colonies is a reproducible characteristic of these communities.

The nutrient and redox conditions of seawater differ quite dramatically from those in the interior of a Trichodesmium colony (Paerl \& Bebout 1988), and different metabolic strategies are likely to be required to thrive in either setting. In contrast to seawater, the interior of puff- and tuft-type colonies is more reducing (as measured by cellular tetrazolium salt reduction and $\mathrm{O}_{2}$-microelectrode measurements) and becomes anoxic during the night (Paerl \& Bebout 1988, Paerl et al. 1989). For this reason alone, it is not surprising that bacteria commonly observed in marine picoplankton clone library datasets are absent in our Trichodesmium clone libraries. Specifically, abundant Sargasso Sea picoplankter ecotypes SAR11, SAR 86, Prochlorococcus, or Synechococcus 
identified by previous workers (Treusch et al. 2009, Carlson et al. 2009) were not detected in our libraries. The OTUs we recovered cluster more closely with clones and isolates from various benthic environments; in particular, we detected numerous clones that are most similar to those associated with sponges (e.g. uncultured Cyanobacteria and uncultured Gammaproteobacteria corresponding to GenBank accession nos. EF630220 and EF629832; Mohamed et al. 2008) and corals (e.g. uncultured Gammaproteobacteria and uncultured Verrucomicrobia corresponding to GenBank accession nos. FJ202161 and FJ203414; Sunagawa et al. 2009). We did not find close relationships between members of our library and common surface associated or algal associated organisms (e.g. specific members of the Roseobacteria clade [Mayali et al. 2008, Wagner-Döbler et al. 2009] or an epibiont isolated from the surface of Trichodesmium in the Caribbean Sea [GenBank accession no. ACNZ01000108]).

A quarter of the clones (excluding those related to Trichodesmium) recovered in the puff-colony library shared $\leq 90$ PSI with nearest neighbors in GenBank. The community associated with the tuft colonies contained an even greater proportion of novel sequences; $81 \%$ of clone sequences share $\leq 90$ PSI with their neighbors in GenBank. Only $21 \%$ and $9 \%$ of OTUs from the puff-colony and tuft-colony library, respectively, share 97 PSI or greater with their nearest GenBank relatives. These results are similar to those obtained during a study of the bacterial flora associated with another filamentous $\mathrm{N}_{2}$-fixing cyanobacterium, Nodularia, in which the majority of epibiont clones associated with Nodularia represented novel taxa (Tuomainen et al. 2006).

Archaea were conspicuously absent from the Trichodesmium colonies. Euryarchaea may represent up to $30 \%$ of the microbial community in the upper $100 \mathrm{~m}$ of the open ocean water column (Frigaard et al. 2006), and Crenarchaea are one of the most abundant groups of organisms in the ocean when bathyand mesopelagic communities are considered (Karner et al. 2001) and can be important nitrifiers (Nicol \& Schleper 2006). T. thiebautii is known to migrate vertically in the water column over the diel cycle (Villareal \& Carpenter 1990), and Trichodesmium spp. have been observed at depths of $100 \mathrm{~m}$ and greater (Letelier \& Karl 1998, Davis \& McGillicuddy 2006), the edge of the crenarchaeotal range in oligotrophic waters (Karner et al. 2001). It is interesting that such important nitrifying organisms as the Crenarchaea or other relatives to known nitrifying bacteria, such as the genera Nitrosospira, or
Nitrosococcus, appear not to participate in nitrogen cycling in association with the ocean's most abundant nitrogen fixer. It has been posited that light could inhibit the nitrifying processes and could be a major reason why nitrifying Bacteria and Archaea are typically not found in the euphotic zone (Ward 1985, Mincer et al. 2007). In the case of Trichodesmium, which may have the ability to vertically migrate to higher light regions during daylight hours via gas vesicle buoyancy (Villareal \& Carpenter 1990), this could be a particularly difficult environment for a nitrifier to inhabit. Our lack of archaeal 16S rRNA gene sequence signal in our libraries is echoed in our recent and ongoing metagenomic characterization of wild Trichodesmium spp., where Archaea were also found to be absent or exceedingly rare (T. Mincer, S. Dyhrman \& B. Van Mooy unpubl. data).

There have been reports of eukaryotes associated with Trichodesmium colonies, but despite our best efforts, we were unable to amplify any eukaryotic SSU rRNA gene sequences from either the tuft or puff Trichodesmium community DNA (e.g. Sheridan et al. 2002). It is possible that eukaryotes may be less tightly associated with the colonies and more easily separated during the sample preparation process. It is important to consider that our samples were collected under non-bloom conditions, and the contribution of Archaea and eukaryotes might increase during a bloom event.

We detected several types of bacteria that are seemingly ubiquitous on living surfaces in the ocean, namely, Alphaproteobacteria, Gammaproteobacteria, and members of the Bacteroidetes. The presence of Alphaproteobacteria is not surprising as many members of this group are opportunistic colonizers and opportunitrophs (Polz et al. 2006) known to colonize surfaces and form biofilms (Buchan et al. 2005, Dang et al. 2008). Members of the order Rhodobacterales, which comprise a majority of the puff-colony-associated alphaproteobacterial sequences (79\%) and half of the tuft-colony-associated alphaproteobacterial sequences $(50 \%)$ detected in the present study, have been identified as ubiquitous early colonizers of surfaces in the oceans (Dang et al. 2008); it is striking that the Rhodobacterales contribute to only half of the alphaproteobacterial clones associated with the tuftcolony sample. Members of a specific clade within the Rhodobacterales, the Roseobacter clade, are of particular interest from the standpoint of microbial community development as they are known to produce antibacterial compounds and have been shown to communicate using acylated homoserine lactones, 
activities which may considerably impact the development of a biofilm community (Gram et al. 2002, Dang et al. 2008, Hmelo 2010).

In addition to Alphaproteobacteria, we detected Gammaproteobacteria and Deltaproteobacteria in the puff-colony library. Gammaproteobacteria, belonging to the Thiotrichales, were detected only in the puff-colony library (no Gammaproteobacteria were detected in the tuft-colony library), which was surprising because Gammaproteobacteria are generally very common on marine surfaces, including particles and particularly algae (Fisher et al. 1998, Dang \& Lovell 2000, Tuomainen et al. 2006, Sapp et al. 2007, Dang et al. 2008). Two deltaproteobacterial clones were detected within the puff-colony library displaying closest relatives in GenBank to uncultivated organisms cloned from benthic environments (e.g. sponges, sediments, and biofilms at hydrothermal vents). The nearest cultivars of these deltaproteobacterial clones were related to the bactivorous Bdellovibrio genus at $87 \%$; however, based upon these data, it is unclear if bactivory occurs in the Trichodesmium phylosphere.

In our tuft-colony samples, we observed abundant cyanobacterial community members in addition to Trichodesmium, including a group distantly related to Limnothrix (92 PSI). Cyanobacterial filaments described as Phormidium-like or Plectonema-like have been reported in association with Trichodesmium colonies numerous times (Paerl et al. 1989, Siddiqui et al. 1992, Dyhrman et al. 2002, Hewson et al. 2009, Hynes et al. 2009), although to our knowledge, no absolute phylogenetic identification has been ascribed to this group. In contrast to our tuftcolony sample, we detected no cyanobacterial OTUs other than those related to $T$. thiebautii in the puffcolony sample. However, in the puff-colony sample, we did detect significant numbers of OTUs related to other possible phototrophic groups, such as the members of the Roseobacter clade of the Alphaproteobacteria, known to be aerobic anoxygenic phototrophs (Buchan et al. 2005). Within the tuft-library, we did not detect OTUs that clustered with Roseobacterclade genera (Buchan et al. 2005).

In one published report within which puffs and tufts were examined independently, Sheridan et al. (2002) noted that the matrix of puff colonies contained bacteria and microflagellates, whereas the matrix of tuft colonies contained bacteria and cyanobacterial filaments. Siddiqui et al. (1992) noted that while contaminating cyanobacterial filaments were present within both colony types, they were significantly more abundant and more reliably asso- ciated with tuft colonies (Sheridan et al. 2002). Thus, both our observations and those from the literature indicate that it may be common for tuft colonies to host additional cyanobacterial species other than Trichodesmium, although the role of these additional Cyanobacteria remain unclear.

The 2 libraries constructed in the present study, representative of the 2 colony morphotypes collected at BATS, do not contain any common OTUs at the 97 PSI threshold. Previous research has concluded that bacterial density (Sheridan et al. 2002), enzyme activities (Nausch 1996, Stihl et al. 2001), and redox gradients from the outside to the inside of the colony (Paerl et al. 1989) differ substantially between puff and tuft colonies. These variations should lead to significant differences in the types of ecological niches provided by the 2 types of colonies. Our data are thus consistent with the hypothesis that puff colonies and tuft colonies can host very different environments on a microbial scale. However, our samples were aggregated from 10 morphologically identical colonies, and thus, we cannot speculate as to the extent of colony-to-colony variability within a given morphotype. An alternative albeit unlikely explanation that would also satisfy our data is that tuft and puff colonies are ecologically equivalent and that all 20 individual colonies collected in the present study host mutually exclusive bacterial flora.

A recent survey of the microbial diversity associated with the marine alga Ulva australis determined that 6 individuals selected from the same waters had nearly mutually exclusive flora associated with them (Burke et al. 2011). In turn, algal-associated species were mutually exclusive with seawater species (Burke et al. 2011). Burke et al. (2011) propose an explanation drawing on lottery competition theory (Sale 1976). They suggest that a guild of bacteria, a group that contains a high degree of ecological redundancy, exists whose members could all exploit the unique niche provided by the surface of $U$. australis. We suggest that this same mechanism may explain the differences we observed between our puff- and tuft-colony clone libraries if the 2 types of colonies provide equivalent niches. Perhaps the essential services required by Trichodesmium can be fulfilled by a variety of bacteria that all compete for settlement on its surface, consistent with lottery competition theory. This hypothesis remains to be tested by evaluating the bacterial communities associated with a number of individual colonies of both morphotypes. Unfortunately, we were unable to extract a sufficient amount of epibiont DNA from a single colony to perform this analysis. 
The high species richness of seawater reflects a great number of low-abundance free-living bacteria, many of which may not actively participate in the biogeochemical cycling of elements in seawater (Pedrós-Alió 2006). The bacteria that are abundant on Trichodesmium may have at one time been 'seeded' from these low-abundance members of the seawater community (i.e. the ones least likely to be represented in a cultivation-independent analysis of seawater). From our data, it is impossible to determine where the seedbank for the unusual Trichodesmium associated sequences lie, whether within the Trichodesmium particulate community itself or the within the community of rare OTUs associated with the ambient seawater community.

In conclusion, the data we present here indicate that Trichodesmium-associated bacterial communities are distinct from other marine pelagic and benthic microbial communities. Both the lack of major seawater taxa and the high abundance of novel OTUs suggest that the bacterial epibionts of Trichodesmium spp. inhabit a unique niche which remains to be explored. These data provide a phylogenetic basis for investigations of these adaptive strategies.

Acknowledgements. We gratefully acknowledge the assistance of M. Miller for microbial strain maintenance and media preparation. We also thank E. Webb and 2 anonymous reviewers, whose comments significantly improved this manuscript. We are also grateful to $\mathrm{M}$. Lomas and the BATS team for affording us a berth on their cruise and for the assistance of the captain and crew of the RV 'Atlantic Explorer'. This work was funded by grants to T.J.M. and B.A.S.V.M. from the WHOI Ocean Life Institute and the National Science Foundation (OCE-0825407) and an award to T.J.M. from The Penzance Endowed Fund in Support of Assistant Scientists.

\section{LITERATURE CITED}

Altschul S, Madden T, Schaffer A, Zhang J, Zhang Z, Miller W, Lipman J (1997) Gapped BLAST and PSI-BLAST: a new generation of protein database search programs. Nucl Acids Res 25:3389-3402

Behrens S, Losekann T, Pett-Ridge J, Weber PK and others (2008) Linking microbial phylogeny to metabolic activity at the single-cell level by using enhanced element labeling-catalyzed reporter deposition fluorescence in situ hybridization (EL-FISH) and NanoSIMS. Appl Environ Microbiol 74:3143-3150

> Berman-Frank I, Rosenberg G, Levitan O, Haramaty L, Mari $\mathrm{X}$ (2007) Coupling between autocatalytic cell death and transparent exopolymeric particle production in the marine cyanobacterium Trichodesmium. Environ Microbiol 9:1415-1422
Buchan A, Gonzalez JM, Moran MA (2005) Overview of the marine Roseobacter lineage. Appl Environ Microbiol 71: 5665-5677

Burke C, Thomas T, Lewis M, Steinberg P, Kjelleberg S (2011) Composition, uniqueness and variability of the epiphytic bacterial community of the green alga Ulva australis. ISME J 5:590-600

Capone DG, Zehr JP, Paerl HW, Bergman B, Carpenter EJ (1997) Trichodesmium, a globally significant marine cyanobacterium. Science 276:1221-1229

Carlson CA, Morris R, Parsons R, Treusch AH, Giovannoni SJ, Vergin K (2009) Seasonal dynamics of SAR11 populations in the euphotic and mesopelagic zones of the northwestern Sargasso Sea. ISME J 3:283-295

Carpenter EJ, Harvey HR, Fry B, Capone DG (1997) Biogeochemical tracers of the marine cyanobacterium Trichodesmium. Deep-Sea Res I 44:27-38

Carpenter EJ, Subramaniam A, Capone DG (2004) Biomass and primary productivity of the cyanobacterium Trichodesmium spp. in the tropical N Atlantic ocean. Deep-Sea Res I 51:173-203

Chao A (1987) Estimating the population size for capturerecapture data with unequal catchability. Biometrics 43: 783-791

Chao A, Yang MCK (1993) Stopping rules and estimation for recapture debugging with unequal failure rates. Biometrika 80:193-201

> Chisholm S, Olson R, Zettler E, Goericke R (1988) A novel free-living prochlorophyte abundant in the oceanic euphotic zone. Nature 334:340-343

Cole JR, Chai B, Marsh TL, Farris RJ and others (2003) The Ribosomal Database Project (RDP-II): previewing a new autoaligner that allows regular updates and the new prokaryotic taxonomy. Nucleic Acids Res 31: 442-443

- Dang H, Lovell CR (2000) Bacterial primary colonization and early succession on surfaces in marine waters as determined by amplified rRNA gene restriction analysis and sequence analysis of 16S rRNA genes. Appl Environ Microbiol 66:467-475

- Dang H, Li T, Chen M, Huang G (2008) Cross-ocean distribution of Rhodobacterales bacteria as primary surface colonizers in temperate coastal marine waters. Appl Environ Microbiol 74:52-60

> Davis CS, McGillicuddy DJ Jr (2006) Transatlantic abundance of the $\mathrm{N}_{2}$-fixing colonial cyanobacterium Trichodesmium. Science 312:1517-1520

$>$ DeLong EF, Preston CM, Mincer T, Rich V and others (2006) Community genomics among stratified microbial assemblages in the ocean's interior. Science 311: 496-503

- Dyhrman ST, Webb EA, Anderson DM, Moffett JW, Waterbury JB (2002) Cell-specific detection of phosphorus stress in Trichodesmium from the western North Atlantic. Limnol Oceanogr 47:1832-1836

> Fisher MM, Wilcox LW, Graham LE (1998) Molecular characterization of epiphytic bacterial communities on charophycean green algae. Appl Environ Microbiol 64: 4384-4389

> Frigaard NU, Martinez A, Mincer TJ, DeLong EF (2006) Proteorhodopsin lateral gene transfer between marine planktonic Bacteria and Archaea. Nature 439:847-850

> Giovannoni SJ, Britschgi TB, Moyer CL, Field KG (1990) Genetic diversity in Sargasso Sea bacterioplankton. Nature 345:60-63 
Good IJ (1953) The population frequencies of species and the estimation of population parameters. Biometrika 40: 237-264

> Gram L, Grossart HP, Schlingloff A, Kiorboe T (2002) Possible quorum sensing in marine snow bacteria: production of acylated homoserine lactones by Roseobacter strains isolated from marine snow. Appl Environ Microbiol 68: 4111-4116

> Herbst V, Overbeck J (1978) Metabolic coupling between the alga Oscillatoria redekei and accompanying bacteria. Naturwissenschaften 65:598-599

> Hewson I, Govil SR, Capone DG, Carpenter EJ, Fuhrman JA (2004) Evidence of Trichodesmium viral lysis and potential significance for biogeochemical cycling in the oligotrophic ocean. Aquat Microb Ecol 36:1-8

> Hewson I, Poretsky RS, Dyhrman ST, Zielinski B and others (2009) Microbial community gene expression within colonies of the diazotroph, Trichodesmium, from the Southwest Pacific Ocean. ISME J 3:1286-1300

Hmelo L (2010). Microbial interactions associated with biofilms attached to Trichodesmium spp. and detrital particles in the ocean. PhD thesis, Massachusetts Institute of Technology, Woods Hole, MA

Huber T, Faulkner G, Hugenholtz P (2004) Bellerophon: a program to detect chimeric sequences in multiple sequence alignments. Bioinformatics 20:2317-2319

Hynes AM, Chappell PD, Dyhrman ST, Doney SC, Webb EA (2009) Cross-basin comparison of phosphorus stress and nitrogen fixation in Trichodesmium. Limnol Oceanogr 54:1438-1448

Karl D, Letelier R, Tupas L, Dore J, Christian J, Hebel D (1997) The role of nitrogen fixation in biogeochemical cycling in the subtropical North Pacific Ocean. Nature 388:533-538

Karner MB, DeLong EF, Karl DM (2001) Archaeal dominance in the mesopelagic zone of the Pacific Ocean. Nature 409:507-510

> Letelier R, Karl D (1996) Role of Trichodesmium spp. in the productivity of the subtropical North Pacific Ocean. Mar Ecol Prog Ser 133:263-273

> Letelier RM, Karl DM (1998) Trichodesmium spp. physiology and nutrient fluxes in the North Pacific subtropical gyre. Aquat Microb Ecol 15:265-276

Ludwig W, Strunk O, Westram R, Richter L and others (2004) ARB: a software environment for sequence data. Nucleic Acids Res 32:1363-1371

> Mayali X, Franks PJS, Azam F (2008) Cultivation and ecosystem role of a marine Roseobacter clade-affiliated cluster bacterium. Appl Environ Microbiol 74: 2595-2603

> Mincer TJ, Church MJ, Taylor LT, Preston C, Karl DM, DeLong EF (2007) Quantitative distribution of presumptive archaeal and bacterial nitrifiers in Monterey Bay and the North Pacific Subtropical Gyre. Environ Microbiol 9: 1162-1175

> Mohamed NM, Enticknap JJ, Lohr JE, McIntosh SM, Hill RT (2008) Changes in bacterial communities of the marine sponge Mycale laxissima on transfer into aquaculture. Appl Environ Microbiol 74:1209-1222

> Morris R, Vergin K, Cho J, Rappé M (2005) Temporal and spatial response of bacterioplankton lineages to annual convective overturn at the Bermuda Atlantic Time-series study site. Limnol Oceanogr 50:1687-1696

> Nausch M (1996) Microbial activities on Trichodesmium colonies. Mar Ecol Prog Ser 141:173-181
Nicol GW, Schleper C (2006) Ammonia-oxidising Crenarchaeota: important players in the nitrogen cycle? Trends Microbiol 14:207-212

Paerl HW (1982). Interactions with bacteria. In: Carr NG, Whitton BA (eds) The biology of cyanobacteria. University of California Press, Los Angeles, CA, p 441-461

> Paerl HW, Bebout BM (1988) Direct measurement of $\mathrm{O}_{2-}$ depleted microzones in marine Oscillatoria: relation to $\mathrm{N}_{2}$ fixation. Science 241:442-445

> Paerl HW, Gallucci KK (1985) Role of chemotaxis in establishing a specific nitrogen-fixing cyanobacterial-bacterial association. Science 227:647-649

> Paerl HW, Bebout BM, Prufert LE (1989) Bacterial associations with marine Oscillatoria sp. (Trichodesmium sp.) populations: ecophysiological implications. J Phycol 25: 773-784

> Pedrós-Alió C (2006) Marine microbial diversity: Can it be determined? Trends Microbiol 14:257-263

Pielou EC (1966) The measurement of diversity in different types of biological collections. J Theor Biol 13:131-144

Polz MF, Hunt DE, Preheim SP, Weinreich DM (2006) Patterns and mechanisms of genetic and phenotypic differentiation in marine microbes. Philos Trans R Soc Lond B 361:2009-2021

Pommier T, Canback B, Riemann L, Bostrom K and others (2007) Global patterns of diversity and community structure in marine bacterioplankton. Mol Ecol 16:867-880

Roe KL, Barbeau K, Mann EL, Haygood MG (2012) Acquisition of iron by Trichodesmium and associated bacteria in culture. Environ Microbiol 14:1681-1695

Sale P (1976) Reef fish lottery. Nat Hist 85:60-65

- Sapp M, Schwaderer AS, Wiltshire KH, Hoppe HG, Gerdts G, Wichels A (2007) Species-specific bacterial communities in the phycosphere of microalgae? Microb Ecol 53: 683-699

Sheridan C, Steinberg D, Kling G (2002) The microbial and metazoan community associated with colonies of Trichodesmium spp.: a quantitative survey. J Plankton Res 24:913-922

> Siddiqui P, Bergman B, Carpenter E (1992) Filamentous cyanobacterial associates of the marine planktonic cyanobacterium Trichodesmium. Phycologia 31:326-337

> Simmons TL, Coates RC, Clark BR, Engene N and others (2008) Biosynthetic origin of natural products isolated from marine microorganism-invertebrate assemblages. Proc Natl Acad Sci USA 105:4587-4594

Sohm JA, Webb EA, Capone DG (2011) Emerging patterns of marine nitrogen fixation. Nat Rev Microbiol 9:499-508

> Stein JL, Marsh TL, Wu KY, Shizuya H, DeLong EF (1996) Characterization of uncultivated prokaryotes: isolation and analysis of a 40-kilobase-pair genome fragment from a planktonic marine archaeon. J Bacteriol 178: $591-599$

> Stevenson BS, Waterbury JB (2006) Isolation and identification of an epibiotic bacterium associated with heterocystous Anabaena cells. Biol Bull 210:73-77

Stihl A, Sommer U, Post AF (2001) Alkaline phosphatase activities among populations of the colony-forming diazotrophic cyanobacterium Trichodesmium spp. (Cyanobacteria) in the Red Sea. J Phycol 37:310-317

Sunagawa S, DeSantis TZ, Piceno YM, Brodie EL and others (2009) Bacterial diversity and White Plague Diseaseassociated community changes in the Caribbean coral Montastraea faveolata. ISME J 3:512-521 
Suzuki MT, Giovannoni SJ (1996) Bias caused by template annealing in the amplification of mixtures of 16S rRNA genes by PCR. Appl Environ Microbiol 62: 625-630

Thompson JR, Marcelino LA, Polz MF (2002) Heteroduplexes in mixed-template amplifications: formation, consequence and elimination by 'reconditioning PCR'. Nucleic Acids Res 30:2083-2088

Treusch AH, Vergin KL, Finlay LA, Donatz MG and others (2009) Seasonality and vertical structure of microbial communities in an ocean gyre. ISME J 3:1148-1163

Tuomainen J, Hietanen S, Kuparinen J, Martikainen PJ, Servomaa K (2006) Community structure of the bacteria associated with Nodularia sp. (Cyanobacteria) aggregates in the Baltic Sea. Microb Ecol 52:513-522

Villareal TA, Carpenter EJ (1990) Diel buoyancy regulation in the marine diazotrophic cyanobacterium Trichodes-

Editorial responsibility: Douglas Capone,

Los Angeles, California, USA mium thiebautii. Limnol Oceanogr 35:1832-1837

Wagner-Döbler I, Ballhausen B, Berger M, Brinkhoff $\mathrm{T}$ and others (2009) The complete genome sequence of the algal symbiont Dinoroseobacter shibae: a hitchhiker's guide to life in the sea. ISME J 4:61-77

Ward BB (1985) Light and substrate concentration relationships with marine ammonium assimilation and oxidation rates. Mar Chem 16:301-316

Waterbury JB (1991). The cyanobacteria: isolation, purification, and identification. In: Dworkin M, Falkow $\mathrm{S}$, Rosenberg E, Schleifer KH, Stackebrandt E (eds) The prokaryotes, 2nd edn. Springer-Verlag, New York, NY, p 2058-2078

Yu Y, Breitbart M, McNairnie P, Rohwer F (2006) FastGroupII: a web-based bioinformatics platform for analyses of large 16S rDNA libraries. BMC Bioinformatics 7:57 doi:10.1186/1471-2105-7-57

Submitted: August 1, 2011; Accepted: May 1, 2012

Proofs received from author(s): July 3, 2012 